\title{
Regional and Seasonal Characteristics of the Recent Expansion of the Tropics
}

\author{
KEVIN M. GRISE \\ Department of Environmental Sciences, University of Virginia, Charlottesville, Virginia \\ SEAN M. DAVIS \\ NOAA Earth System Research Laboratory, and Cooperative Institute for Research in Environmental \\ Sciences, University of Colorado Boulder, Boulder, Colorado \\ PAul W. STATEN \\ Department of Earth and Atmospheric Sciences, Indiana University, Bloomington, Indiana
}

ORI ADAM

Hebrew University of Jerusalem, Jerusalem, Israel

(Manuscript received 3 February 2018, in final form 17 May 2018)

\begin{abstract}
In recent decades, the subtropical edges of Earth's Hadley circulation have shifted poleward. Some studies have concluded that this observed tropical expansion is occurring more rapidly than predicted by global climate models. However, recent modeling studies have shown that internal variability can account for a large fraction of the observed circulation trends, at least in an annual-mean, zonal-mean framework. This study extends these previous results by examining the seasonal and regional characteristics of the recent poleward expansion of the Hadley circulation using seven reanalysis datasets, sea level pressure observations, and surface wind observations. The circulation has expanded the most poleward during summer and fall in both hemispheres, with more zonally asymmetric circulation trends occurring in the Northern Hemisphere (NH). The seasonal and regional characteristics of these observed trends generally fall within the range of trends predicted by climate models for the late twentieth and early twenty-first centuries, and in most cases, the magnitude of the observed trends does not exceed the range of interdecadal trends in the models' control runs, which arise exclusively from internal variability. One exception occurs during NH fall when large observed poleward shifts in the atmospheric circulation over the North Atlantic sector exceed nearly all trends projected by models. While most recent NH circulation trends are consistent with a change in phase of the Pacific decadal oscillation (PDO), the observed circulation trends over the North Atlantic instead reflect 1) large natural variability unrelated to the PDO and/or 2) a climate forcing (or the circulation response to that forcing) that is not properly captured by models.
\end{abstract}

\section{Introduction}

Numerous lines of observational evidence suggest that Earth's Hadley circulation has expanded poleward since 1979 , acting to push subtropical dry regions farther poleward in both the Northern Hemisphere $(\mathrm{NH})$ and Southern Hemisphere (SH; Seidel et al. 2008; Davis and Rosenlof 2012; Birner et al. 2014; Lucas et al. 2014). The magnitude of the recent tropical expansion reported by individual studies varies greatly, ranging from $\sim 0.2^{\circ}$ to

Corresponding author: Kevin M. Grise,kmg3r@virginia.edu $2^{\circ}$ latitude decade ${ }^{-1}$ because of differences in the datasets and methodologies used (Davis and Rosenlof 2012; Birner et al. 2014). Some studies have concluded that the magnitude of the observed tropical expansion far exceeds the predictions of global climate models (Johanson and $\mathrm{Fu}$ 2009; $\mathrm{Hu}$ et al. 2013), calling into question the ability of models to accurately capture general circulation trends driven by climate change.

Models suggest that a number of different anthropogenic forcings contributed to the poleward expansion of the Hadley circulation over the late twentieth century. First, increasing atmospheric greenhouse gases likely 
contributed to a poleward expansion of the Hadley circulation in both the $\mathrm{NH}$ and $\mathrm{SH}$ (Hu et al. 2013; Tao et al. 2016). Second, stratospheric ozone depletion likely contributed to a poleward expansion of the SH Hadley circulation during DJF (Son et al. 2010; Kang et al. 2011; McLandress et al. 2011; Polvani et al. 2011; Min and Son 2013). Third, although more uncertain, changes in anthropogenic aerosol forcing may also have contributed to a poleward expansion of the NH Hadley circulation (Allen et al. 2012; Kovilakam and Mahajan 2015). Yet, overall, the magnitude of the tropical expansion predicted by climate models, taking into account anthropogenic forcings for the late twentieth century, is (on average) substantially smaller than most estimates of observed tropical expansion over this period (Johanson and Fu 2009; $\mathrm{Hu}$ et al. 2013). Note, however, that the large uncertainty in the magnitude of the observed tropical widening complicates the assessment of model performance (Adam et al. 2014; Quan et al. 2014).

Recent studies have indicated that the apparent discrepancy between global climate models and observations may arise from internal variability in the climate system. Using both single-model and multimodel ensembles, these studies have shown that, when individual model runs are considered, observational estimates of recent tropical expansion do indeed fall within the range of trends predicted by models (Adam et al. 2014; Garfinkel et al. 2015; Allen and Kovilakam 2017; Davis and Birner 2017). Trends from observations and individual model runs encompass tropical expansion driven by both anthropogenic forcing and natural variability, whereas trends based on an average of model runs encompass only the tropical expansion driven by anthropogenic forcing (as the contribution from natural variability is averaged out across model runs). A number of studies have concluded that the shift in the Pacific decadal oscillation (PDO) toward its negative phase in recent decades has contributed to the large rate of observed tropical expansion, which is supported by evidence from model runs forced with observed sea surface temperatures (SSTs; Grassi et al. 2012; Adam et al. 2014; Allen et al. 2014; Waugh et al. 2015; Allen and Kovilakam 2017; Amaya et al. 2018; Mantsis et al. 2017).

The majority of previous studies have focused on the relative roles of natural variability and anthropogenic forcing to recent observed circulation trends within an annual-mean, zonal-mean framework. However, the recent expansion of the tropics has a seasonally varying component (Davis and Rosenlof 2012; Allen and Kovilakam 2017) and varies greatly by longitude (Lucas and Nguyen 2015; Manney and Hegglin 2018). The purpose of this study is to provide a more comprehensive view of the relative contributions of natural variability and anthropogenic forcing to the observed widening of the tropics by focusing on the seasonal and regional characteristics of the trends.

The poleward expansion of the Hadley circulation in recent decades has been largest during summer and fall in both hemispheres (Fu et al. 2006; $\mathrm{Hu}$ and $\mathrm{Fu}$ 2007; Davis and Rosenlof 2012; Allen and Kovilakam 2017). Global climate models suggest that many forcings that drive tropical expansion impart a unique seasonality to the trends. For example, any tropical expansion driven by stratospheric ozone depletion should maximize during the SH summer (DJF) season (e.g., Polvani et al. 2011). Tropical expansion driven by increasing greenhouse gases should maximize during the summer (DJF) and fall (MAM) seasons in the $\mathrm{SH}$ and during the fall (SON) season in the NH (Hu et al. 2013; Davis et al. 2016; Grise and Polvani 2016; Tao et al. 2016). Finally, the influence of the PDO on the width of the tropics should be largest during the equinox seasons (Grassi et al. 2012).

The regional characteristics of the recent tropical expansion have only been explored by a small number of studies, but based on this limited evidence, the largest contributions to the observed widening of the tropics appear to arise from the sector stretching from the South Atlantic Ocean (Chen et al. 2014; Choi et al. 2014), across Africa (Manney and Hegglin 2018), and eastward toward Asia, Australia, and the western Pacific Ocean (Choi et al. 2014; Lucas and Nguyen 2015). As with the seasonal characteristics of the recent circulation trends, the regional characteristics of the trends depend strongly on the underlying forcing. While the tropical expansion associated with increasing greenhouse gases is expected to be approximately zonally symmetric in the $\mathrm{SH}$, models indicate that the poleward circulation expansion associated with increasing greenhouse gases will be more strongly focused over the Atlantic sector in the NH (Simpson et al. 2014; Grise and Polvani 2014). In contrast, natural variability in the edge of the Hadley circulation (such as that associated with the PDO) is dominated by the Asia-Pacific sector (Lucas and Nguyen 2015; Nguyen et al. 2018).

In this study, we show that the seasonal and regional characteristics of the observed poleward expansion of the Hadley circulation generally fall inside the range of projections from global climate models, consistent with the annual-mean, zonal-mean results documented in previous studies (Adam et al. 2014; Garfinkel et al. 2015; Allen and Kovilakam 2017; Davis and Birner 2017; Mantsis et al. 2017). However, our results identify one exception: poleward circulation trends over the North Atlantic basin during the fall (SON) season, which lie 
TABLE 1. Listing of the observational datasets used in this study.

\begin{tabular}{llll}
\hline \multicolumn{1}{c}{ Dataset } & Years available & Metrics available & \\
\hline ERA-Interim & 1979-present & All & Citations \\
NCEP-DOE & 1979-present & All & NCEP (2002), Kanamitsu et al. (2002) \\
MERRA-2 & 1980-present & All & GMAO (2015), Gelaro et al. (2017) \\
JRA-55 & 1958-present & All & JMA (2013), Kobayashi et al. (2015) \\
CFSR & $1979-2010$ & All & Saha et al. (2010a,b) \\
20CR & $1851-2014$ & SLP & Compo et al. (2011), NOAA (2014) \\
ERA-20C & $1900-2010$ & SLP, $\mathrm{U}_{\text {sfc }}$ & ECMWF (2014), Poli et al. (2016) \\
HadSLP2r & $1850-$ present & SLP & Allan and Ansell (2006), Met Office Hadley Centre (2013) \\
WASWind & $1950-2011$ & $\mathrm{U}_{\text {sfc }}(\mathrm{NH}$ only) & Tokinaga and Xie (2011), Tokinaga (2012) \\
\hline
\end{tabular}

outside the range of nearly all projected trends from models. Section 2 describes the data and methods. Section 3 examines the seasonality of the recent zonalmean circulation trends in both observations and models, and section 4 examines the regional characteristics of those trends. Section 5 provides a detailed discussion of the results, with an emphasis on the trends over the North Atlantic basin during SON. Section 6 provides a summary and concluding thoughts.

\section{Data and methods}

\section{a. Data}

To estimate the observed rate of tropical expansion, we use monthly mean data from nine observation-based datasets: five full-input reanalyses (ERA-Interim, NCEP-DOE, MERRA-2, JRA-55, and CFSR); two surface-input reanalyses [20CR and ECMWF twentieth century reanalysis (ERA-20C)], which assimilate only observed surface pressures, SSTs, sea ice concentrations, and marine winds (ERA-20C only); gridded marine and land sea level pressure observations (HadSLP2r); and gridded marine surface wind observations [Waveand Anemometer-Based Sea Surface Wind (WASWind)]. The details of each dataset are listed in Table 1.

We also use monthly mean output from 26 global climate models that participated in CMIP5 (WCRP 2011; Taylor et al. 2012; see listing of models in Table 2). For this study, we select the 26 models with at least one ensemble member from each of the following four scenarios: 1) preindustrial control (hundreds of years of unforced variability), 2) AMIP (atmosphere-only experiments forced with observed 1979-2008 SST and sea ice trends), 3) historical (driven by 1850-2005 forcings), and 4) RCP8.5 (driven by projected 2006-2100 forcings, which reach a radiative forcing of $8.5 \mathrm{~W} \mathrm{~m}^{-2}$, in excess of preindustrial levels, in 2100). Unless otherwise noted, we use the first ensemble member (r1i1p1) from each model for each of these four scenarios. We also examine two additional scenarios, which are only available from a subset of the 26 models: 1) historical runs forced only by increasing greenhouse gases (17 models) and 2) historical runs forced only by anthropogenic aerosols (9 models). Except for the AMIP runs, all model runs are fully coupled (i.e., they include a dynamic, interactive ocean).

\section{b. Methods}

To quantify poleward shifts in the tropospheric circulation, we use four metrics:

1) Sea level pressure (SLP): latitude of the zonal-mean SLP maximum in the subtropics of each hemisphere

2) $\Psi_{500}$ : latitude where the zonal-mean meridional streamfunction $(\Psi)$ at $500 \mathrm{hPa}$ transitions from the thermally direct Hadley circulation to the thermally indirect Ferrel circulation in each hemisphere

3) $U_{\text {sfc }}$ : latitude where the zonal-mean tropical surface easterlies transition to zonal-mean midlatitude surface westerlies in each hemisphere

4) Eddy-driven jet (EDJ): latitude of the zonal-mean zonal-wind maximum at $850 \mathrm{hPa}$ in each hemisphere

Monthly mean, zonal-mean fields are averaged seasonally or annually prior to the calculation of the metrics. To calculate the metrics, we follow the procedures of Adam et al. (2018a,b); further details are provided in the appendix.

The SLP, $\Psi_{500}$, and $U_{\text {sfc }}$ metrics are direct or indirect measures of the movement of the poleward edges of the Hadley circulation (Solomon et al. 2016; Davis and Birner 2017; Waugh et al. 2018). The EDJ metric is not strictly a measure of Hadley circulation expansion, but rather that of a poleward shift of the midlatitude eddydriven jet. We include results for the EDJ metric here, as some recent circulation trends may be more accurately described in terms of a poleward shift of the eddy-driven jet (rather than a poleward shift of the Hadley cell edge). In practice, the EDJ metric is highly correlated with the other three metrics, particularly in the SH during DJF (Kang and Polvani 2011; Staten and Reichler 2014; Solomon et al. 2016; Davis and Birner 2017). 
TABLE 2. Listing of the CMIP5 models and the number of ensemble members from each model used in this study.

\begin{tabular}{|c|c|c|c|c|c|}
\hline Model name & piControl & Historical + RCP8.5 & AMIP & Historical GHG & Historical aerosol \\
\hline ACCESS1.0 & 1 & 1 & 1 & 0 & 0 \\
\hline ACCESS1.3 & 1 & 1 & 2 & 3 & 0 \\
\hline BCC_CSM1.1 & 1 & 1 & 3 & 1 & 0 \\
\hline BCC_CSM1.1(m) & 1 & 1 & 3 & 0 & 0 \\
\hline BNU-ESM & 1 & 1 & 1 & 1 & 0 \\
\hline CanESM2 (CanAM4) & 1 & 5 & 4 & 5 & 5 \\
\hline CCSM4 & 1 & 6 & 6 & 3 & 3 \\
\hline CESM1 (CAM5) & 1 & 3 & 2 & 1 & 3 \\
\hline CMCC-CM & 1 & 1 & 3 & 0 & 0 \\
\hline CNRM-CM5 & 1 & 5 & 1 & 6 & 0 \\
\hline CSIRO Mk3.6.0 & 1 & 10 & 10 & 5 & 5 \\
\hline EC-EARTH & 1 & 9 & 1 & 0 & 0 \\
\hline FGOALS-g2 & 1 & 1 & 1 & 1 & 1 \\
\hline GFDL CM3 & 1 & 1 & 3 & 3 & 3 \\
\hline GISS-E2-R & 1 & 5 & 12 & 5 & 5 \\
\hline HadGEM2-ES (HadGEM2-A) & 1 & 4 & 6 & 4 & 0 \\
\hline INM-CM4.0 & 1 & 1 & 1 & 0 & 0 \\
\hline IPSL-CM5A-LR & 1 & 4 & 6 & 5 & 1 \\
\hline IPSL-CM5A-MR & 1 & 1 & 3 & 3 & 0 \\
\hline IPSL-CM5B-LR & 1 & 1 & 1 & 0 & 0 \\
\hline MIROC5 & 1 & 5 & 2 & 0 & 0 \\
\hline MIROC-ESM & 1 & 1 & 1 & 3 & 0 \\
\hline MPI-ESM-LR & 1 & 3 & 3 & 0 & 0 \\
\hline MPI-ESM-MR & 1 & 1 & 3 & 0 & 0 \\
\hline MRI-CGCM3 & 1 & 1 & 3 & 1 & 0 \\
\hline NorESM1-M & 1 & 1 & 3 & 1 & 1 \\
\hline
\end{tabular}

In this study, we do not consider metrics of tropical expansion related to the upper-tropospheric wind, tropopause height, outgoing longwave radiation (OLR), and precipitation minus evaporation $(P-E)$ fields. These metrics have been used in some previous studies, but we exclude them here for several reasons. First, interannual variability in the position of the uppertropospheric subtropical jet and subtropical tropopause break are poorly correlated with variability in the Hadley cell edge (Solomon et al. 2016; Davis and Birner 2017; Waugh et al. 2018), and global climate models show little robust poleward expansion of these metrics over the twenty-first century (Davis and Birner 2017). Second, trends in any OLR-based metric are dominated by global temperature warming and are not a robust metric of circulation changes (Waugh et al. 2018). Finally, although the latitude where zonal-mean $P-E$ changes sign in the subtropics $(P-E=0)$ is well correlated with variability in the Hadley cell edge in models (Solomon et al. 2016; Waugh et al. 2018), the $P-E$ field is difficult to accurately estimate using reanalysis data or other observation-based products (see Seviour et al. 2018).

To quantify variability in the PDO, we use the index introduced by Mantua et al. (1997), which is defined as the leading principal component (PC) time series of SST anomalies poleward of $20^{\circ} \mathrm{N}$ in the North Pacific basin.
Prior to calculating the PC time series, the seasonal cycle is removed from the SST data, and then the global-mean SST anomaly is subsequently removed from each grid point. For the observations, the PDO index is calculated using the Hadley Centre Sea Ice and SST dataset (HadISST1; Met Office Hadley Centre 2000; Rayner et al. 2003).

\section{Seasonal characteristics of recent tropical expansion}

In this section, we examine the seasonality of the recent expansion of the tropics from a zonal-mean perspective and then compare and contrast the observed trends with those from CMIP5 models. In the following section, we consider the zonal structure of the observed and model trends.

The colored symbols in Fig. 1 show estimates of recent tropical expansion derived from the nine observational datasets listed in Table 1. Trends are shown for the 1980-2008 period. This time period is chosen because 1) $1980-2010$ is the common time period shared by all datasets in Table 1 and 2) 2008 is the end date of the CMIP5 AMIP scenario. We have verified that similar trends occur over periods with end dates ranging from 2005 to the present (not shown). For brevity, we focus on results for the 1980-2008 period but note key 
1980-2008 Trends: Observed vs. CMIP5 Historical+RCP8.5
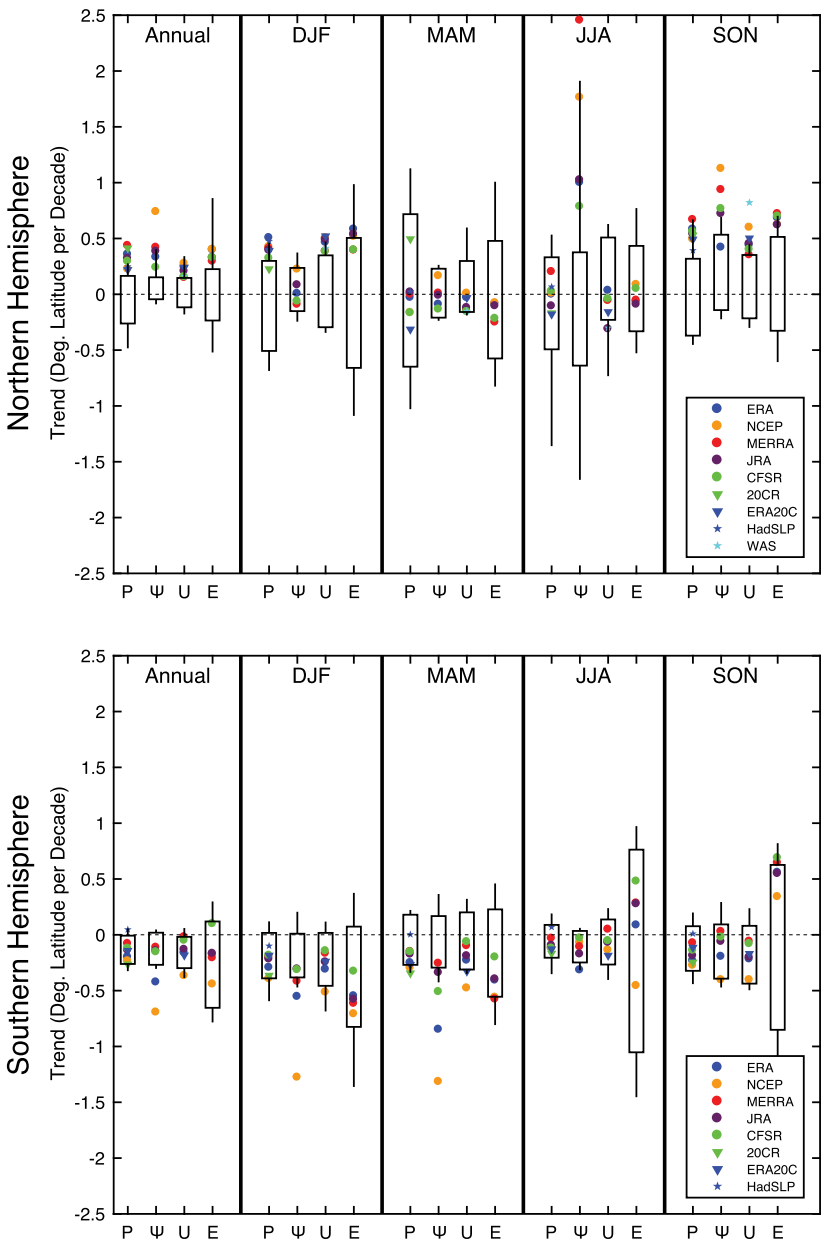

1980-2008 Trends: Observed vs. CMIP5 AMIP
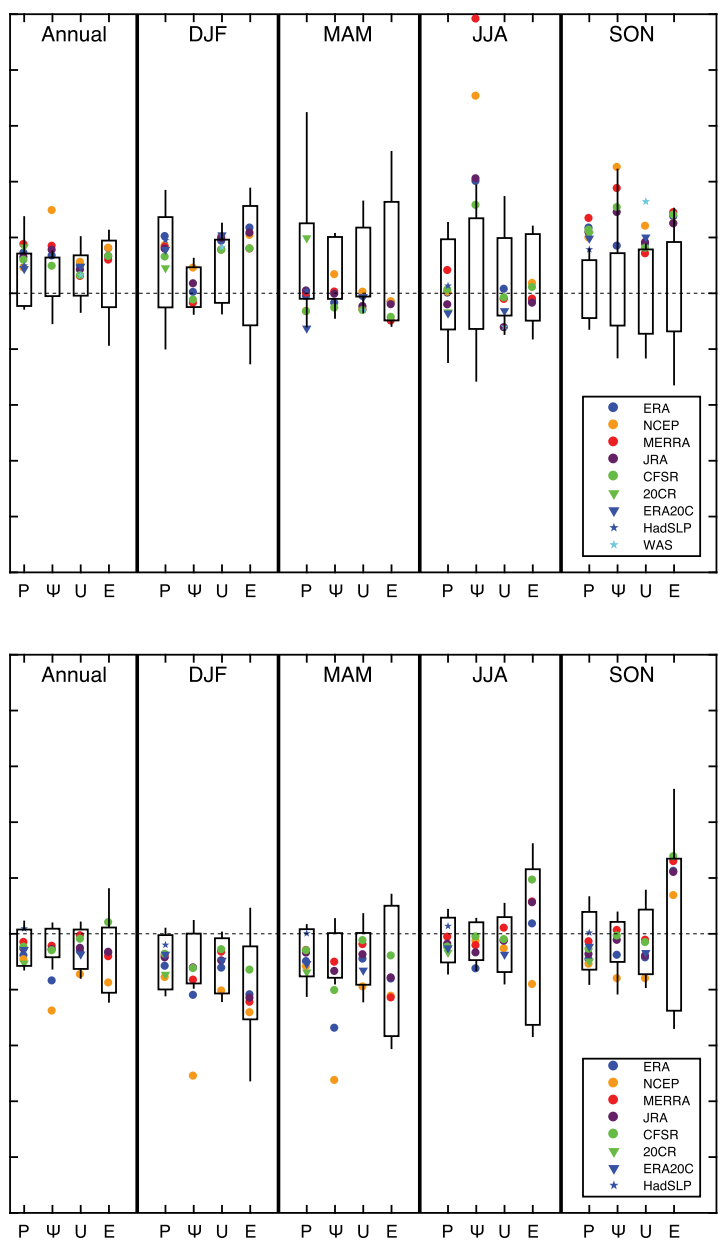

FIG. 1. Trends in four metrics of the edge of the tropics: $\operatorname{SLP}(P), \Psi_{500}(\Psi), U_{\text {sfc }}(U)$, and EDJ $(E)$ for the period 1980-2008. The colored symbols indicate trends estimated from the reanalysis and observational products listed in Table 1, the boxes indicate the 10th-90th percentiles of trends from CMIP5 models (historical + RCP8.5 in the left column and AMIP in the right column), and the whiskers indicate the upper and lower 10th percentiles of the model trends. Results are shown for the annual mean and the four seasonal means for (top row) Northern Hemisphere and (bottom row) Southern Hemisphere.

exceptions where the choice of end date significantly affects the trends.

Consistent with previous studies, all four metrics of tropical expansion from observations (as defined in section $2 b$ ) suggest a poleward expansion of the Hadley circulation in both hemispheres, but the magnitudes and seasonality vary widely by dataset and metric (e.g., Davis and Rosenlof 2012). When all four metrics are examined together, the largest poleward expansion occurs in the $\mathrm{NH}$ during SON and in the SH during DJF and MAM ( $\mathrm{Hu}$ and $\mathrm{Fu}$ 2007; Allen and Kovilakam 2017). If a single metric is examined, different conclusions may result because of the inherent properties of that particular metric. For example, there are large poleward trends in the $\mathrm{NH} \Psi_{500}$ metric during JJA (Allen and Kovilakam 2017), but this large summertime trend is not mirrored in the other three metrics and likely reflects the difficulty in defining the $\Psi_{500}$ metric in the NH during this season (see Grise and Polvani 2016). Hence, it is important to look at observed trends using multiple metrics as opposed to one single metric.

Superposed on the observed trends, Fig. 1 shows the 10th-90th percentiles of trends (boxes) and the upper and lower 10th percentiles of trends (whiskers) from CMIP5 models. The left column shows the range of the models' projected trends from the CMIP5 historical scenario (which ends in 2005 and has been appended with three years of the RCP8.5 scenario to extend the model time series until 2008), and the right column shows the range of the models' projected trends from the CMIP5 AMIP scenario. The results in Fig. 1 reveal that the range of trends projected by the models encompasses most of the 
observational estimates for each metric and season. Overall, there is no indication that global climate models are systematically unable to capture the magnitude of the observed trends.

This result is in agreement with the annual-mean findings of Adam et al. (2014) and Davis and Birner (2017) for CMIP5 models, and Garfinkel et al. (2015) and Allen and Kovilakam (2017) for single model ensembles. Earlier studies had argued that the models were underestimating the observed trends (Johanson and $\mathrm{Fu}$ 2009; $\mathrm{Hu}$ et al. 2013). However, these earlier conclusions resulted from 1) comparing the multimodel mean trend (which captures only the forced response) with the observed trend (which captures the forced response, as well as natural variability and any error in the observations), 2) quantifying the observed trend using the $\Psi_{500}$ metric in older generation reanalyses (see orange dots in Fig. 1), and/or 3) quantifying the observed trend using an OLR-based metric, which is not a robust metric of circulation changes (Waugh et al. 2018). Interestingly though, the observed trends during NH SON, while not outside the range of model trends, almost all lie within the upper 10th percentile of model trends for all four metrics, a point to which we will return in the following sections.

Previous studies have also argued that model runs forced with observed SSTs (particularly those over the eastern tropical Pacific Ocean) provide better estimates of the observed trends than fully coupled models forced with historical radiative forcings, as these runs by construction capture observed changes in modes of coupled atmosphere-ocean variability, including the PDO (Allen et al. 2014; Allen and Kovilakam 2017). The AMIP runs of CMIP5 models on average show slightly larger magnitudes of tropical expansion than the historical runs and better capture the observed trends in the $\mathrm{NH}$ in the annual average and in DJF (Fig. 1, top row). The observed $\mathrm{NH}$ wintertime trends are highly sensitive to the choice of the 1980-2008 period (not shown), and thus it is not surprising that prescribing the SSTs allows the models to have a better representation of the observed trends during this season (and thus also in the annual mean). Nonetheless, the range of the trends across the AMIP runs is on the same order of magnitude (and in some cases larger) than the range of trends across the fully coupled historical runs (cf. left and right columns of Fig. 1). Hence, even if SST variability is prescribed, models can produce a wide range of trends in Hadley cell extent over $\sim 30$-yr periods.

Figure 2 repeats the results from Fig. 1, but now compares the observed 1980-2008 trends with trends from all unique (nonoverlapping) 29-yr periods from the models' control runs. Here, the model trends arise
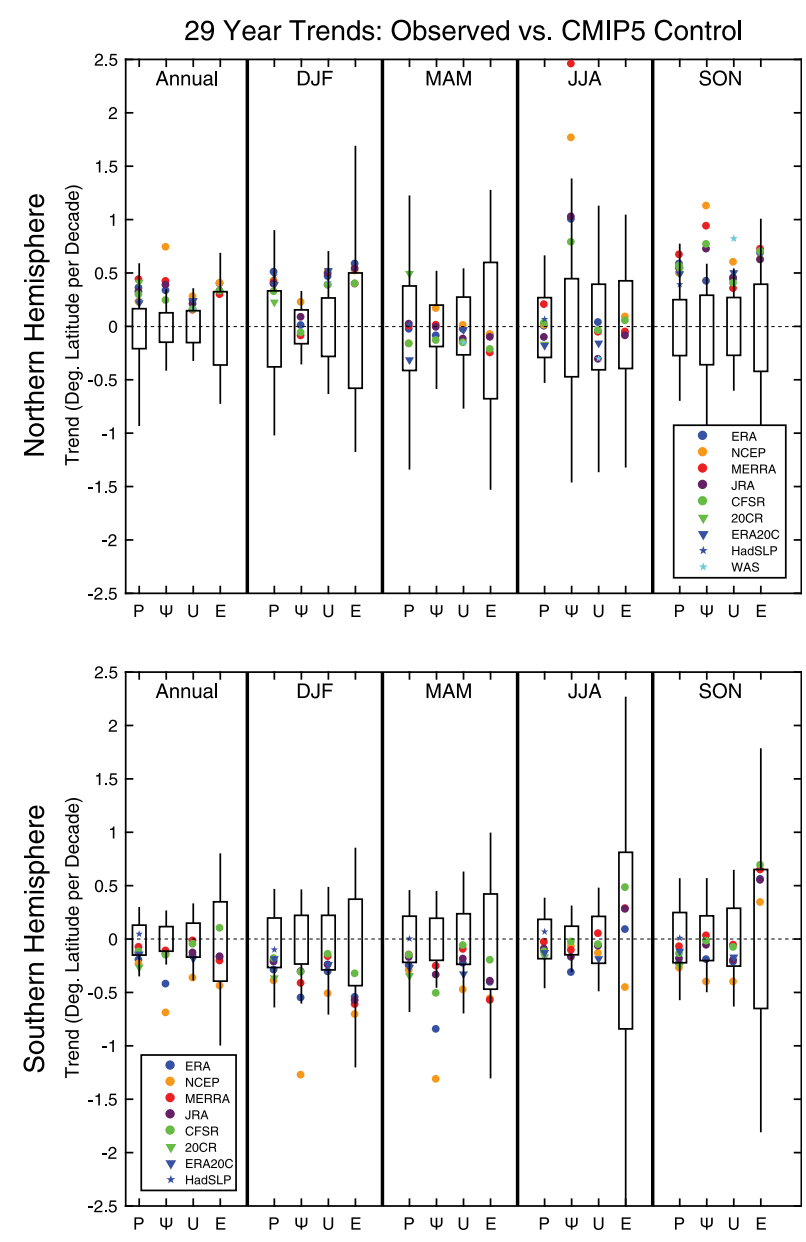

FIG. 2. As in Fig. 1, but comparing the observed 1980-2008 trends with $29-\mathrm{yr}$ trends from the preindustrial control runs of CMIP5 models.

purely from internal variability (no forcing). Again, nearly all of the observed trends are encompassed by the range of model trends in both hemispheres and in all seasons, and thus the observed trends (apart from a small number of outliers) are not large enough to exceed the range of natural variability in the models (see also Quan et al. 2014). Relative to the models' range of natural variability, the observed trends that would be the most unlikely (based on all four metrics) would be the $\mathrm{NH}$ tropical expansion during SON (as mentioned above) and the SH tropical expansion during DJF (Thomas et al. 2015) and MAM. As mentioned in the introduction, the larger tropical expansion in the SH during DJF would be consistent with driving by stratospheric ozone depletion (Polvani et al. 2011; Waugh et al. 2015), and the larger tropical expansion in the $\mathrm{NH}$ during SON and in the $\mathrm{SH}$ during DJF and MAM would be consistent with driving by increasing greenhouse gases (Davis et al. 2016; Grise and Polvani 2016; Tao et al. 2016). 

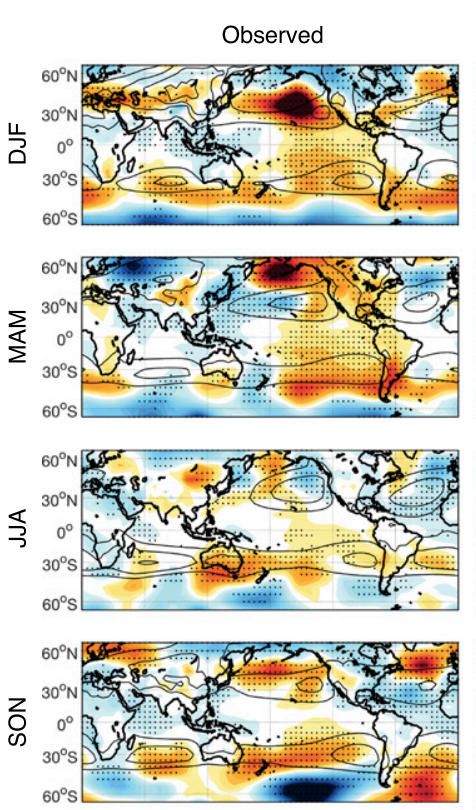

1980-2008 Sea Level Pressure Trends CMIP5 Historical + RCP 8.5
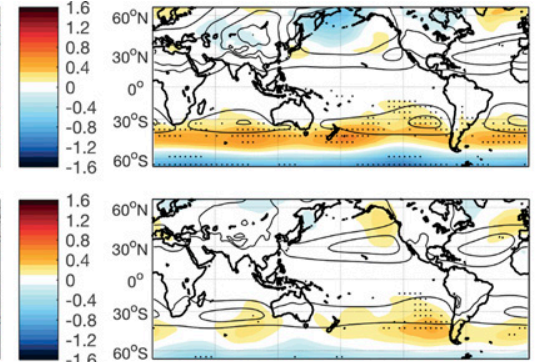

$60^{\circ} \mathrm{S}$
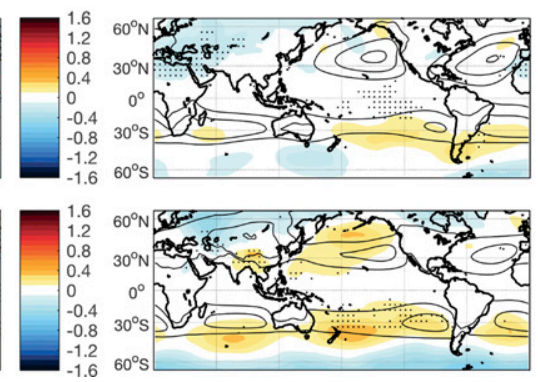
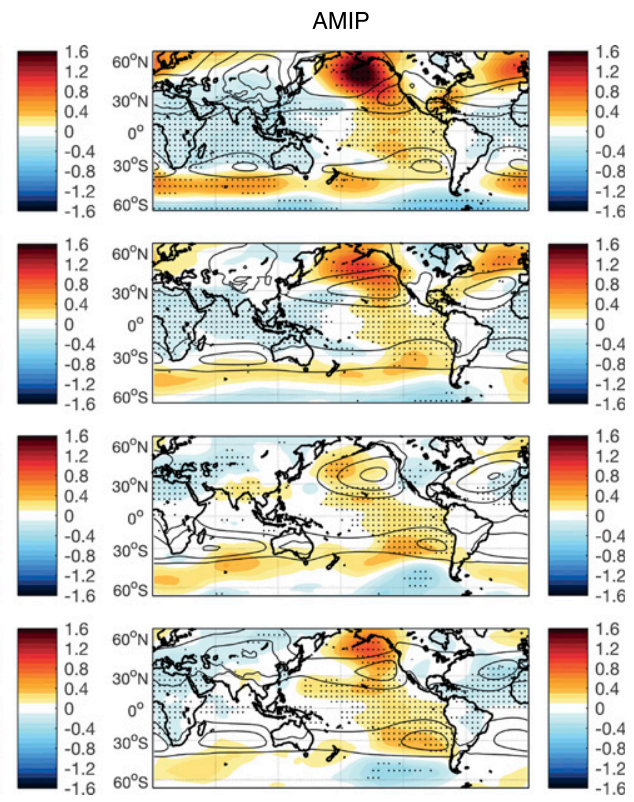

FIG. 3. 1980-2008 sea level pressure trends (in hPa decade ${ }^{-1}$ ) for (left column) observations, (middle column) CMIP5 historical + RCP8.5 runs, and (right column) CMIP5 AMIP runs. Patterns show the mean of eight observational products in the left column and 26 CMIP5 models in the middle and right columns. Stippling indicates where all eight observational products in the left column and $80 \%$ of models in the middle and right columns agree on the sign of the trends. Black contours show the SLP climatology for ERA-Interim in the left column and the multimodel mean in the middle and right columns (values $\geq 1015 \mathrm{hPa}$ are contoured at an interval of $5 \mathrm{hPa}$ ).

In summary, in this section, we have documented estimates of recent tropical expansion from nine observationally based datasets using a zonal-mean perspective. We find that the observed tropical expansion does not exceed the range of trends predicted by global climate models over the same period, even if we examine each season individually. Most importantly, we have shown that the observed tropical expansion does not exceed the range of trends in the models' control runs, and thus one cannot rule out the possibility that the observed trends arise in large part from natural variability. In the next section, we investigate whether these conclusions hold at individual longitudes and not just in the zonal-mean framework.

\section{Regional characteristics of recent tropical expansion}

In this section, we document the spatial characteristics of the recent expansion of the tropics and then compare and contrast the observed trends with those from CMIP5 models. To do this, we follow Choi et al. (2014) and examine trends in the SLP field, as the zonal-mean subtropical subsidence of the Hadley circulation is manifested regionally in semipermanent subtropical high pressure systems (e.g., Karnauskas and Ummenhofer 2014). It is important to note that the regional SLP trends documented here are not exclusively influenced by changes in the Hadley circulation, as they can also be affected by local temperature anomalies as well as by changes in zonally varying overturning circulations (such as the Walker circulation).

The left column of Fig. 3 shows the spatial pattern of observed SLP trends over the period 1980-2008, as averaged over the eight observational datasets in Table 1 with SLP data. The poleward expansion of the Hadley circulation is associated with a poleward shift in the semipermanent subtropical high pressure systems over the oceans of both hemispheres (Schmidt and Grise 2017). Consistent with an expanding Hadley circulation, the observed SLP trends in Fig. 3 (left column) are characterized by 1) a poleward shift in the SH subtropical ridge during most seasons, 2) a poleward shift in the North Pacific subtropical high during all seasons but JJA, and 3) a poleward shift in the North Atlantic subtropical high during DJF and SON. Additionally, there are trends toward a weakening of the North Atlantic subtropical high during most seasons (Hartmann et al. 2013) and a strengthening of the Walker circulation (e.g., L'Heureux et al. 2013).

The middle and right columns of Fig. 3 show the corresponding multimodel mean trends from the historical and AMIP scenarios of CMIP5 models. The historical SLP trends from the fully coupled models 
(Fig. 3, middle column) are weaker than the observed SLP trends (Fig. 3, left column). In the NH, there is little resemblance between the observed and model trends, suggesting that the observed trends are primarily nonforced (or that the circulation response to anthropogenic forcing is not properly captured by the multimodel mean). In the SH, the observed poleward shift of the subtropical ridge over the Southern Ocean appears to be driven in part by anthropogenic forcing, particularly during DJF. The poleward shift of the SH subtropical ridge is consistent with forcing by stratospheric ozone depletion and increasing greenhouse gases (see introduction).

Compared to the fully coupled historical runs, the spatial pattern of SLP trends from the AMIP runs of CMIP5 models are more similar in both pattern and magnitude to those from observations (cf. left and right columns of Fig. 3), particularly over the Pacific and Indian Ocean sectors. Both the observed and AMIP trends are characterized by a poleward shift in the SH subtropical ridge, a poleward shift in the North Pacific subtropical high, and a strengthening of the Walker circulation. These trends closely resemble the SLP anomalies associated with the negative phase of the PDO (see Fig. 7) and support the conclusion that the recent tropical expansion has been strongly affected by natural coupled atmosphere-ocean variability (Allen et al. 2014; Allen and Kovilakam 2017; Amaya et al. 2018; Mantsis et al. 2017). However, the AMIP runs fail to capture most of the observed SLP trends over the Atlantic sector, including the poleward shift of the North Atlantic subtropical high during SON.

The results in Fig. 3 illustrate similarities and differences between the observed and multimodel mean trends, but do not reveal whether some individual models capture the spatial pattern of the observed trends. To investigate this possibility, Fig. 4 shows the trend in the latitude of the SLP maximum at each longitude in the $\mathrm{NH}$; observed SLP shifts as a function of longitude in the SH are shown in Choi et al. (2014) and are not reproduced here. For further details on how the SLP maximum is located at each longitude, please refer to the appendix.

Consistent with Fig. 3 (left column), the observed trends in the location of the SLP maximum at each longitude (Fig. 4, black lines) reveal 1) poleward shifts in the subtropical highs over Europe $\left(0^{\circ}-40^{\circ} \mathrm{E}\right)$ and the Pacific Ocean $\left(150^{\circ} \mathrm{E}-145^{\circ} \mathrm{W}\right)$ during DJF, 2) few poleward shifts in the subtropical highs during MAM and JJA, and 3) poleward shifts in the subtropical highs over the Pacific $\left(140^{\circ}-180^{\circ} \mathrm{E}\right)$ and Atlantic $\left(60^{\circ} \mathrm{W}-0^{\circ}\right)$ Oceans during SON. The trends over the continents have significant variance across observational products, particularly during summer months when there are not clearly defined subtropical high pressure systems in the climatology (Fig. 3, black contours). In Fig. 4, the large trends at longitudes without a well-defined climatological SLP maximum in the subtropics should not be viewed as robust, as they are not consistent across datasets and reflect the high sensitivity of the location of the maximum value to small perturbations in the data.

In general, at all longitudes, the recent observed trends all fall within the envelope of trends projected by the models (cf. black and colored lines in Fig. 4); this is also true in the $\mathrm{SH}$ (not shown). One notable exception occurs over the North Atlantic during SON. As shown in Fig. 3, the multimodel mean of CMIP5 models does not capture the recent poleward shift in the North Atlantic subtropical high during SON. However, Fig. 4 reveals that none of the 26 models (in either the historical or AMIP scenarios) are able to capture the magnitude of the recent North Atlantic SON trends, which are consistent across all eight observational products. Hence, the primary reason that the observed zonal-mean expansion of the tropics during NH SON falls in the upper 10th percentile of model trends (Figs. 1 and 2) is the large poleward shift in the North Atlantic subtropical high during these months that is not captured by the models.

How unusual are the recent trends over the North Atlantic during SON? The results in Fig. 4 only compare the observed trends with those from one ensemble member from each of the 26 CMIP5 models in Table 2. In Fig. 5, we compare the observed poleward shift in the North Atlantic subtropical high during SON (Fig. 4, black lines, averaged over $60^{\circ} \mathrm{W}-0^{\circ}$ ) with the trends from all available ensemble members from each of the 26 models in Table 2 . The observed trends exceed $\sim 99 \%$ of the model trends from the historical runs and $\sim 96 \%$ of the model trends from the AMIP runs. Furthermore, less than $1 \%$ of the 29 -yr periods in the control runs of the models have similar trends as the observations.

In Fig. 6, we provide context for the recent North Atlantic SLP trends within the twentieth-century observational record. Figure 6a plots the 1900-2017 time series of the latitude of the North Atlantic subtropical high during SON from the HadSLP2r dataset, the two twentieth-century reanalyses (20CR and ERA-20C), and JRA-55; nearly identical time series are found for the other reanalyses (not shown). All datasets reveal a steady poleward shift of the North Atlantic subtropical high from the late 1970s until the 2010s that is punctuated by large interannual variability. The large interannual variability arises mostly from midlatitudes, where exceptionally positive SLP anomalies occurred in 2007/08 (Fig. 6b). Despite these large anomalies, our 
1980-2008 Trends: Observed vs. CMIP5 Historical+RCP8.5
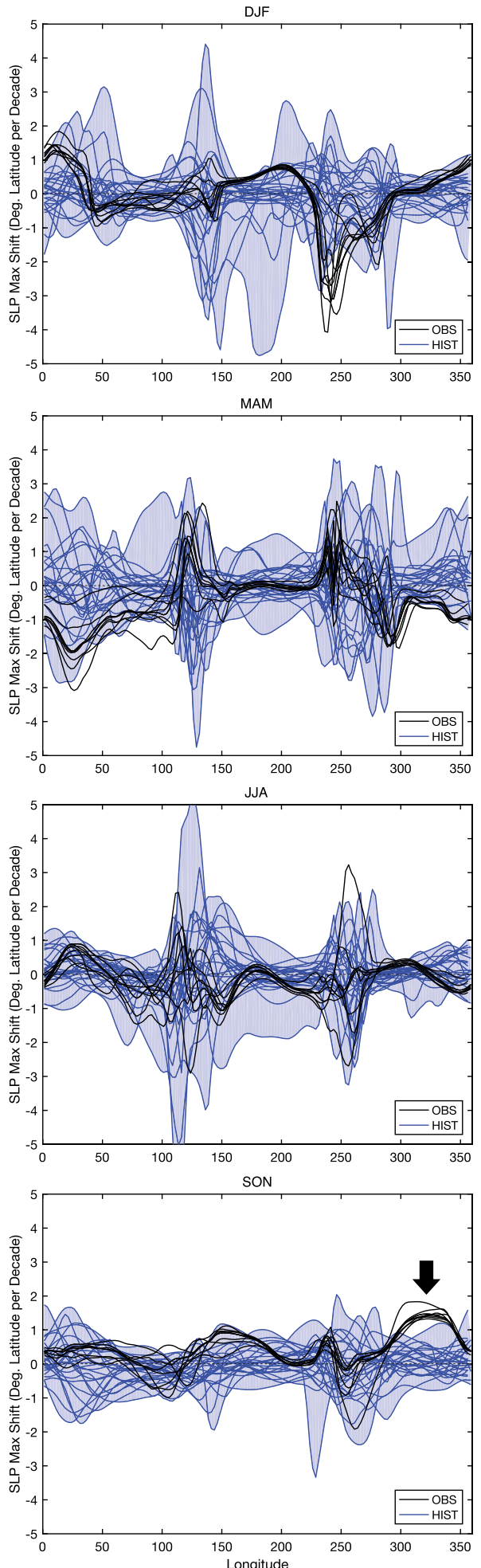

1980-2008 Trends: Observed vs. CMIP5 AMIP
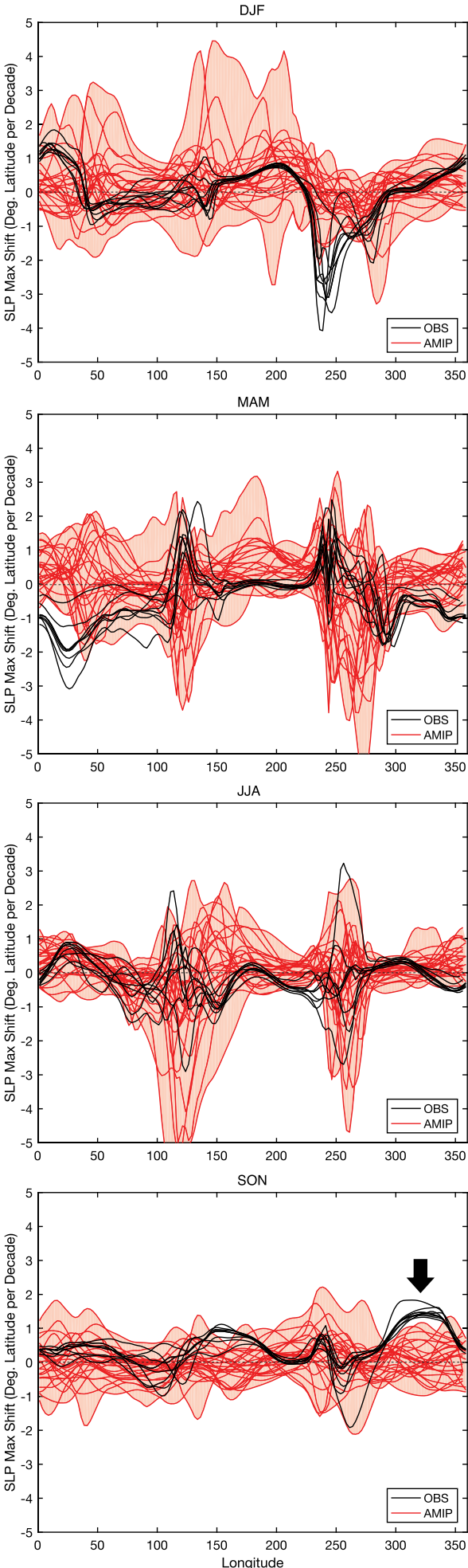

FIG. 4. 1980-2008 trends in the latitude of the NH subtropical sea level pressure maximum at each longitude. Black lines show eight observational products, blue lines show 26 CMIP5 historical + RCP8.5 runs, and red lines show 26 CMIP5 AMIP runs. Colored shading highlights the range of the intermodel spread. 

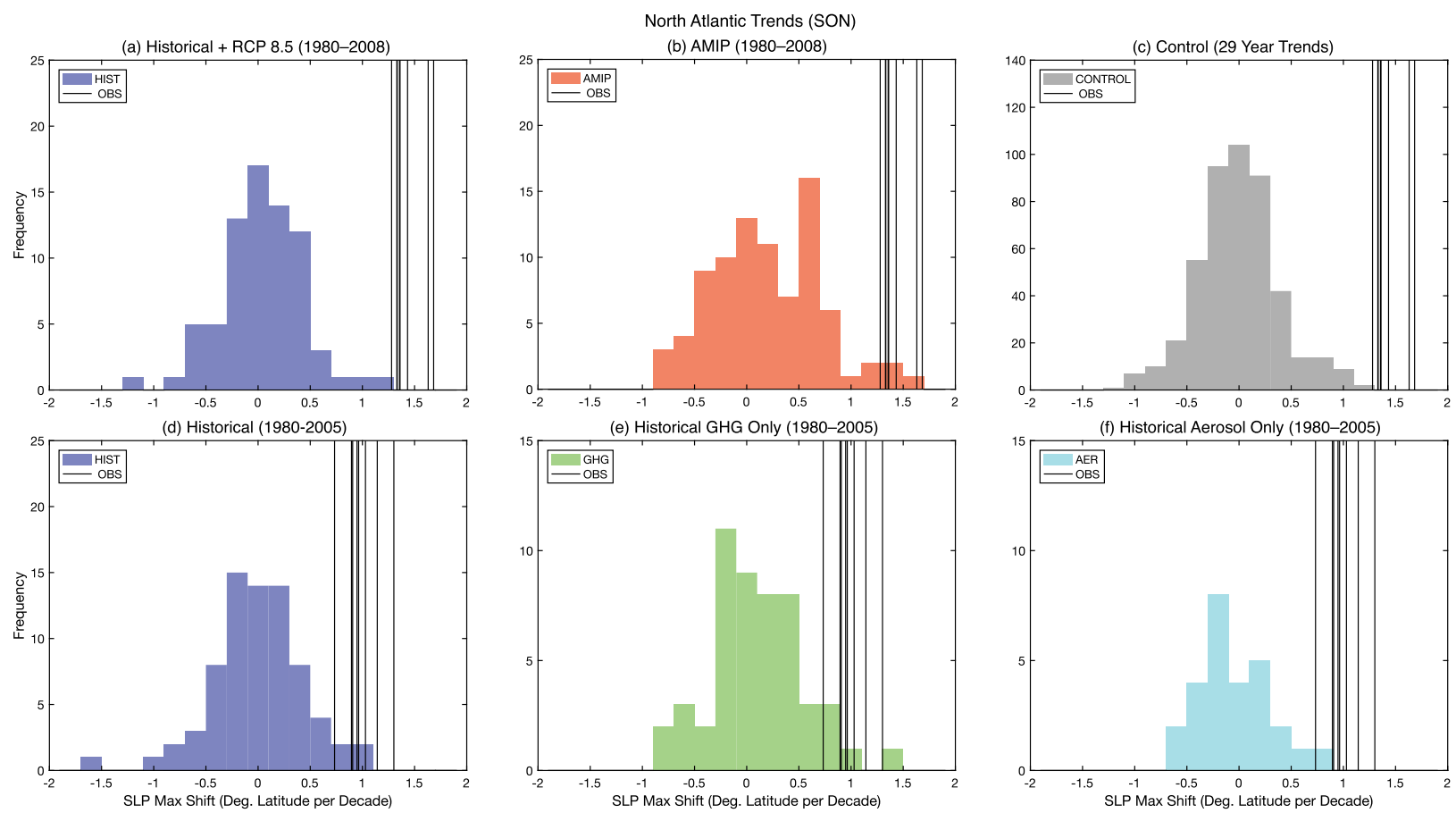

FIG. 5. Trends in the latitude of the subtropical sea level pressure maximum over the North Atlantic Ocean $\left(60^{\circ} \mathrm{W}-0^{\circ}\right)$ for the SON season from all ensemble members of CMIP5 models listed in Table 2: (a) historical + RCP8.5 (1980-2008), (b) AMIP (1980-2008), (c) preindustrial control (29-yr periods), (d) historical (1980-2005), (e) historical greenhouse gas forcing only (1980-2005), and (f) historical anthropogenic aerosol forcing only (1980-2005). Trends from eight observational products are shown as black vertical lines; in (c), the observed trends are for the 1980-2008 period.

conclusions are not sensitive to using 2008 as the end date for the trends. If we instead examine trends for the period 1980-2005, the observed poleward shift of the North Atlantic subtropical high during SON is still greater than $\sim 95 \%$ of the trends from the models' historical runs (Fig. 5d).

The recent poleward shift in the North Atlantic subtropical high appears to arise from negative SLP trends over the subtropical North Atlantic (Fig. 3, bottom left). In this region, there is a consistent longterm decreasing trend in SLP from the mid-1970s until the early 2010s (Fig. 6c). Neglecting large anomalous values during the two World Wars (Fig. 6, gray boxes) when the number of marine surface observations was reduced (Allan and Ansell 2006), the recent subtropical North Atlantic SLP anomalies are among the lowest in these observational datasets. The recent trend may have slowed or stopped within the last five years, but the trend over the 1980-2017 period is still statistically significant at the $95 \%$ confidence level via Student's $t$ test (adjusting for autocorrelation following Santer et al. 2000).

In summary, in this section, we have shown that the recent poleward expansion of the Hadley circulation is associated with notable zonal asymmetries, particularly in the NH. While most of the asymmetries can be captured by model runs forced with observed SSTs, the recent poleward shift in the North Atlantic subtropical high during SON is not captured well by the models (Fig. 4). In fact, even when examining all available ensemble members, the observed SON trends over the North Atlantic are exceedingly rare (Fig. 5). Furthermore, the recent SLP anomalies in the subtropical North Atlantic are unusual within the context of the observed twentieth-century climate record (Fig. 6c). In the following section, we discuss in detail the contributions of natural variability and anthropogenic forcings to the observed trends, focusing on why the observed North Atlantic trends far exceed most model estimates.

\section{Discussion}

The results above demonstrate that the recent expansion of the tropics is not outside of the range of trends predicted by global climate models, even when examining individual seasons and longitudes. One outlier is the large poleward shift in the North Atlantic subtropical high during SON. In this discussion, we evaluate four hypotheses for why the models are underestimating this large observed trend. 

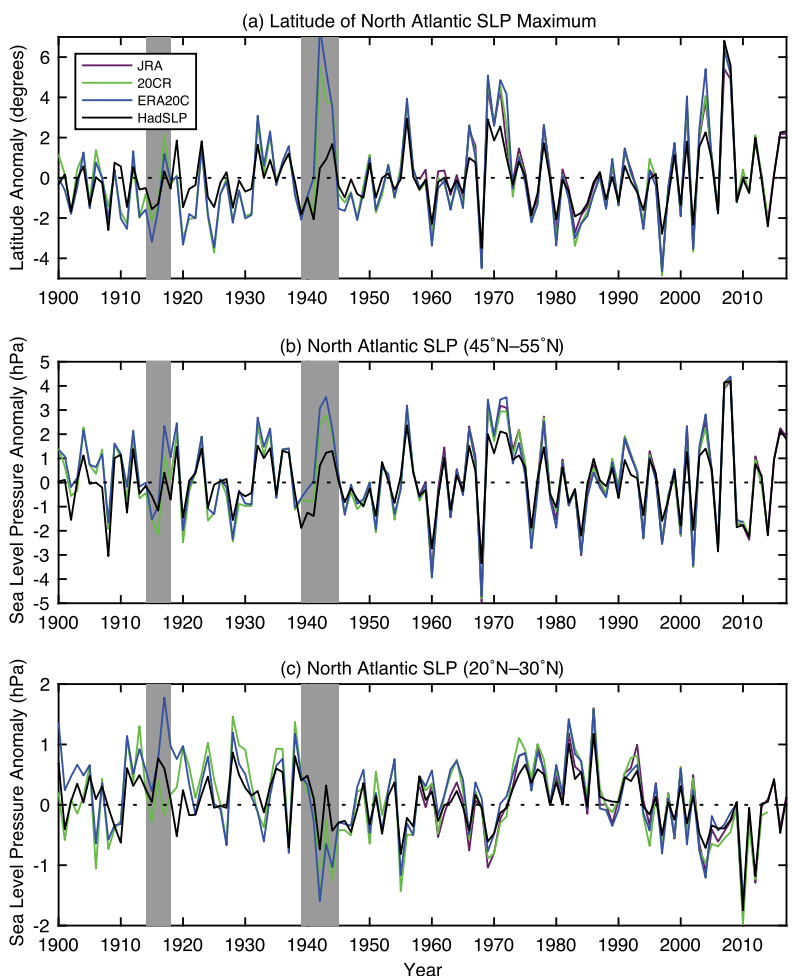

FIG. 6. Observed time series of (a) the latitude of the subtropical sea level pressure maximum over the North Atlantic Ocean $\left(60^{\circ} \mathrm{W}-\right.$ $0^{\circ}$ ), (b) sea level pressure averaged over $60^{\circ} \mathrm{W}-0^{\circ}$ and $45^{\circ}-55^{\circ} \mathrm{N}$, and (c) sea level pressure averaged over $60^{\circ} \mathrm{W}-0^{\circ}$ and $20^{\circ}-30^{\circ} \mathrm{N}$. Values are plotted as anomalies from the 1981-2010 mean. Results are shown for four observational datasets: (purple) JRA-55, (green) 20CR, (blue) ERA-20C, and (black) HadSLP2r. The gray boxes demarcate the periods of World War I and World War II.

\section{a. Hypothesis 1: Global climate models do not properly represent the atmospheric teleconnections associated with the PDO}

As shown in Fig. 3, the recent SLP trends in the AMIP runs of CMIP5 models compare well to those from observations except over the Atlantic Ocean, so potentially the atmospheric teleconnections associated with recent decadal SST variability are misrepresented in models. To test this possibility, in Fig. 7, we show the observed 1980-2008 SLP trends from SON (as shown in Fig. 3, bottom left), along with the component of those trends that is linearly congruent with the PDO (as estimated from both observations and models). To estimate the PDO-congruent trends, we multiply the 1980-2008 trend in the PDO index by the spatial pattern of SLP anomalies associated with interannual variability in the PDO. For the observations, this spatial pattern is calculated by regressing 1900-79 SLP anomalies on the detrended PDO index; for the models, this spatial pattern is calculated by regressing SLP anomalies onto PDO indices calculated from the models' control runs.

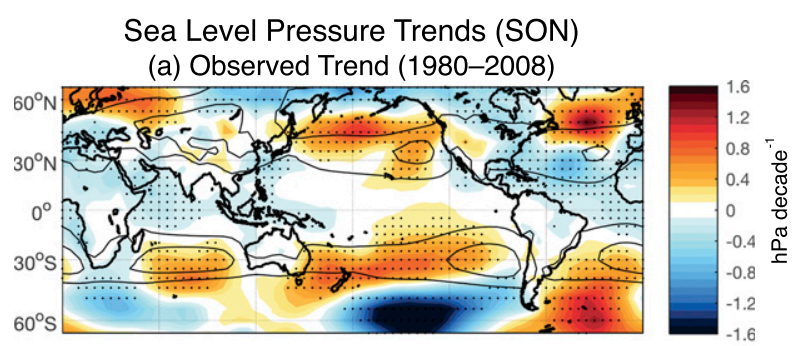

(b) PDO Congruent Trend (Observations)

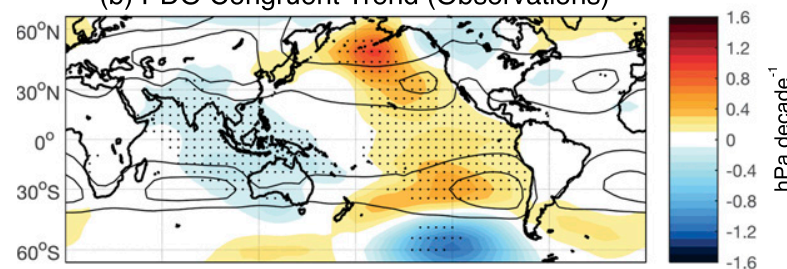

(c) PDO Congruent Trend (Models)

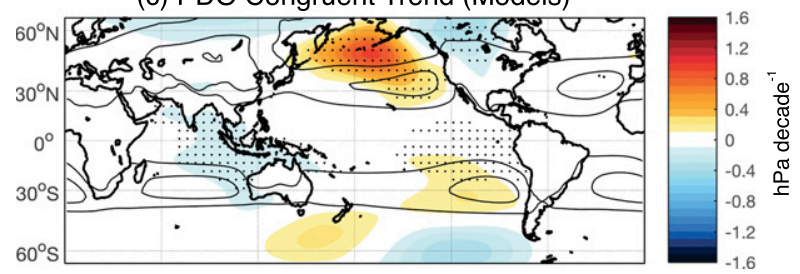

FIG. 7. (a) Observed 1980-2008 SON sea level pressure trends (as in Fig. 3, bottom left). (b) Component of observed SLP trends that are congruent with the 1980-2008 PDO trend, as estimated by multiplying the observed 1980-2008 trend in the PDO index by the regression coefficients of observed 1900-79 SLP anomalies onto a detrended PDO index. Results are shown for the mean of three observational datasets (20CR, ERA-20C, and HadSLP2r), and stippling indicates regions where the regression coefficients from all three datasets are statistically significant at the $95 \%$ level based on Student's $t$ test. (c) As in (b), but based on the regression coefficients from the control runs of CMIP5 models. Results are shown for the mean of 26 models, and stippling indicates regions where the regression coefficients from at least $80 \%$ of the models are statistically significant at the $95 \%$ level. Thin black contours show the (a) ERA-Interim, (b) HadSLP2r, and (c) multimodel mean sea level pressure climatology (values $\geq 1015 \mathrm{hPa}$ are contoured at an interval of $5 \mathrm{hPa}$ ).

The results in Fig. 7 reveal that the atmospheric teleconnections over the North Atlantic associated with the PDO are weak and not statistically significant in both observations and models and are thus unable to explain the magnitude of the recent observed SLP trends during SON (cf. Figs. 7b,c with Fig. 7a). Furthermore, if model uncertainty in PDO teleconnections were contributing to the models' underestimation of the observed trends, one would expect to see a direct relationship between the magnitude of each model's North Atlantic SLP trends in the AMIP scenario and its PDO teleconnections over the North Atlantic. However, no significant correlation is found (not shown). Hence, we find little evidence to suggest that 
improper PDO teleconnections are the reason why models are systematically underestimating the magnitude of the recent SLP trends over the North Atlantic.

\section{b. Hypothesis 2: Global climate models do not properly represent the observed circulation response to anthropogenic forcing}

As noted in the introduction, a key characteristic of global climate model experiments forced with increasing greenhouse gases is a distinct seasonality in $\mathrm{NH}$ circulation trends, with the largest poleward shift in the atmospheric circulation over the North Atlantic occurring during SON (Barnes and Polvani 2013; Simpson et al. 2014; Grise and Polvani 2014, 2016). Consequently, it is possible that the recent SLP trends over the North Atlantic during SON are a response to increasing greenhouse gases and that models are underestimating the sensitivity of the circulation to that forcing. To test this possibility, in Fig. 8, we compare the SLP trends from observations and the historical runs of CMIP5 models (as shown in Fig. 3) with the SLP trends from two of the models' historical single forcing scenarios (greenhouse gas only and anthropogenic aerosol only).

In Fig. 8, the trends are plotted for the 1980-2005 period (as the historical single-forcing runs end in 2005) and only for the nine models with all three scenarios available (see Table 2). The observed SLP trends (Fig. 8a) and the SH SLP trends from the CMIP5 historical runs (Fig. 8b) are very similar to those shown in Fig. 3 (bottom row) for the 1980-2008 period, but the NH SLP trends in Fig. 8b differ greatly. The difference is due largely to the subset of models chosen and not to the difference in periods (19802005 vs 1980-2008) between the two figures (not shown). The late twentieth-century NH SLP trends projected by the historical runs of CMIP5 models are model dependent and not robust across the multimodel ensemble (see stippling in Fig. 3, middle column).

We now examine the SLP trends from the historical runs of CMIP5 models forced only with increasing greenhouse gases (Fig. 8c). The SLP trends driven by greenhouse gas forcing are similar to those driven by all forcings in the $\mathrm{SH}$, but are very different in the $\mathrm{NH}$ (cf. Fig. 8b and Fig. 8c). Notably, there are poleward shifts in the circulation over the Southern Ocean and North Atlantic Ocean, which are weaker but similar to the robust circulation responses to $4 \mathrm{xCO}_{2}$ forcing documented by previous studies (e.g., Grise and Polvani 2014). Over the 1980-2005 period, the majority of models forced only by increasing greenhouse gases shift the North Atlantic subtropical high farther poleward during SON, although the observed trends still exceed $90 \%$ of the trends from all model ensemble members (Fig. 5e).
1980-2005 Sea Level Pressure Trends (SON) (a) Observations

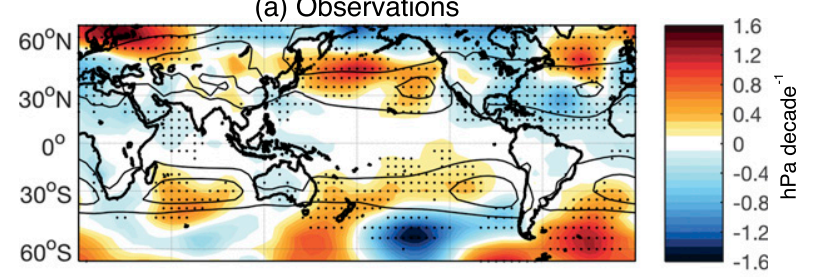

(b) Models (All Forcings)

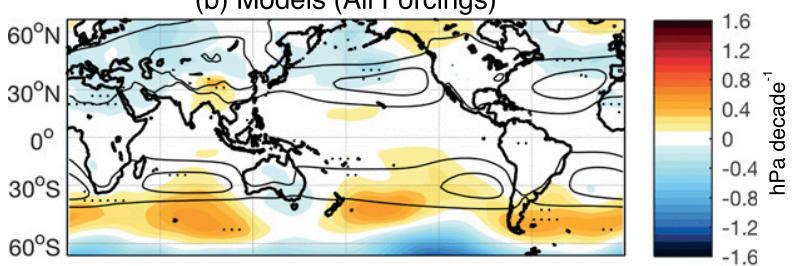

(c) Models (Greenhouse Gases Only)

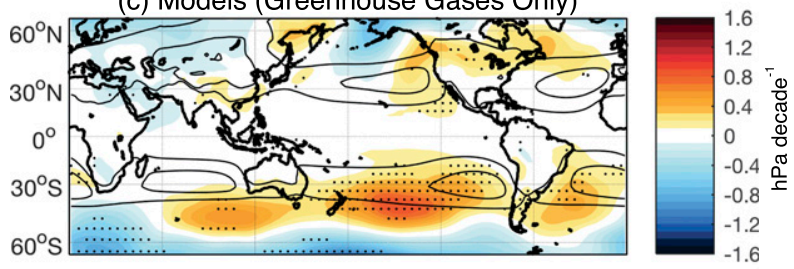

(d) Models (Anthropogenic Aerosols Only)

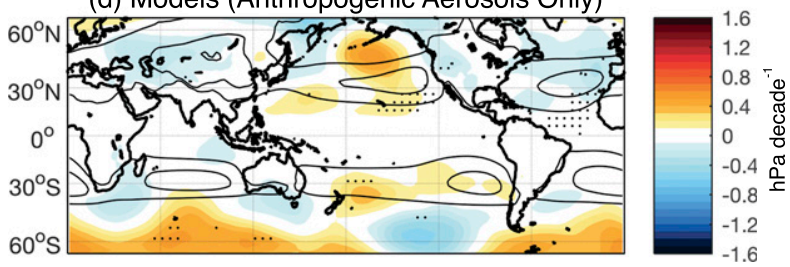

FIG. 8. As in Fig. 3, but for the 1980-2005 sea level pressure trends (in $\mathrm{hPa}$ decade $^{-1}$ ) for the September-November season: (first row) observations, (second row) CMIP5 historical scenario, (third row) CMIP5 historical greenhouse gas-only scenario, and (fourth row) CMIP5 historical anthropogenic-aerosol-only scenario. Model results are only shown for the nine models with all three scenarios available (see Table 2).

Next, we examine the SLP trends from the historical runs of CMIP5 models forced only with changes in anthropogenic aerosols (Fig. 8d). In contrast to greenhouse gas forcing, the most robust circulation responses to aerosol forcing are in the $\mathrm{NH}$, particularly a weakening of the North Atlantic subtropical high (see also Schmidt and Grise 2017). The North Atlantic SLP trends are of opposite sign to those predicted in response to increasing greenhouse gases (cf. Fig. 8c and Fig. 8d) and are reminiscent of the recent observed trends in the same region (Figs. 6c and 8a). Over the 1980-2005 period, a slight majority of models forced only by anthropogenic aerosols shift the North Atlantic subtropical high further equatorward during SON, with only one ensemble member out of 27 exceeding the observed trends (Fig. 5f).

The circulation response to aerosol forcing is highly variable across models, and given the small number of 
models that conducted these runs as well as the different representations of aerosol processes in those models, the mean circulation response shown in Fig. 8d should be viewed with caution. Based on Fig. 8, it appears that late twentieth-century anthropogenic aerosol forcing in CMIP5 models contributes to a negative SLP trend over the North Atlantic during SON (Fig. 8d), leading to a reduced multimodel mean SLP trend in the historical runs of the models (Fig. $8 \mathrm{~b}$ ) relative to the greenhouse gas-only runs (Fig. 8c). If the aerosol forcing (or the atmospheric circulation's sensitivity to that forcing) were incorrect, it could cause the relative roles of greenhouse gas and aerosol forcing to be misrepresented in the historical runs of the models, and thus cause the model trends to be biased relative to observations. Although the AMIP runs of the models capture the influence of the observed aerosol forcing on SSTs, they would similarly be biased to any circulation changes driven by in-atmosphere or land surface heating associated with aerosol forcing and related aerosol-cloud interactions. Overall, the role of aerosol forcing in biasing the historical circulation response in models is a plausible hypothesis that deserves further exploration, particularly given their potential importance in driving North Atlantic climate variability (Booth et al. 2012; Wang et al. 2012).

\section{c. Hypothesis 3: The recent observed North Atlantic trends resulted from large natural variability}

As shown in Fig. 4, the recent observed North Atlantic SLP trends during SON fall outside the range of trends predicted by the first ensemble member of each model, suggesting that the models are unable to capture the magnitude of the recent trends. However, on closer inspection, when examining all available ensemble members from the models, there are a very small number of model runs that do capture the magnitude of the recent trends (Fig. 5). Thus, while the observed North Atlantic trends would be exceedingly rare, they are within the realm of natural variability projected by the models. The coupled versions of the models may misrepresent lowfrequency SST variability, such as that associated with the PDO (Newman et al. 2016) or the Atlantic meridional overturning circulation (Zhang and Wang 2013), but our conclusion remains unchanged if we focus exclusively on the AMIP scenario (Figs. 1 and 4, right column; Fig. 5b), in which models are forced with observed SST variability.

The range of North Atlantic SLP trends projected by the AMIP and greenhouse gas-only runs of the models have the greatest overlap with the observed trends (Figs. 5b,e). In contrast, the range of North Atlantic SLP trends projected by the control and aerosol-only runs barely overlaps the smallest estimates of the observed trends (Figs. 5c,f). Therefore, the models suggest that the observed trends would more likely occur because of large natural variability in a warming climate, particularly when the PDO is shifting toward its negative phase.

It is difficult to completely rule out natural variability when examining circulation trends over $\sim 30$-yr periods (such as 1980-2008). To illustrate this, in Fig. 9, we compare the trends in our four metrics of tropical expansion over the years 2070-2100 in the RCP8.5 runs of the models (i.e., when we expect the forced circulation response to be large) with trends from all unique (nonoverlapping) 31-yr periods from the control runs of the models (as in Fig. 2). Even over the 2070-2100 period, $\sim 30$-yr circulation trends in the models vary widely and are largely encompassed by the range of natural variability from the control runs (Fig. 9, left column). Only over much longer periods, such as 2020-2100, do the circulation trends in the control runs and forced runs begin to diverge from each other, particularly in the $\mathrm{SH}$ (Fig. 9, right column; see also Solomon and Polvani 2016). In the $\mathrm{NH}$, circulation trends over this $\sim 80$-yr period still do not exceed the range of natural variability for most metrics and seasons.

\section{d. Hypothesis 4: The recent observed North Atlantic trends are an artifact of data biases}

Finally, it is possible that the recent observed North Atlantic SLP trends are overestimated and a result of biases in the observational datasets. However, all observational products closely agree on the magnitude of the recent trends in this region (Figs. 4-6), as surface pressure observations are directly assimilated into reanalysis datasets. Furthermore, the North Atlantic is one of the most well-sampled marine environments on the planet (e.g., Allan and Ansell 2006), and thus we have high confidence that the recent North Atlantic SLP trends are physical and much larger than most models capture.

\section{Conclusions}

In this study, we examined the poleward expansion of Earth's Hadley circulation over the late twentieth century and early twenty-first century in both observations and global climate models, focusing on its seasonal and regional characteristics. Consistent with previous studies, we found a sizeable poleward expansion of the Hadley circulation in the observations over this period $\left(\sim 0.2^{\circ}-0.3^{\circ}\right.$ latitude decade ${ }^{-1}$ in each hemisphere in the annual mean). The recent circulation trends have been largest during summer and fall in each hemisphere (Fig. 1; see also Allen and Kovilakam 2017), with the trends being more zonally asymmetric in the NH (Fig. 3).

In general, the magnitude of the recent poleward expansion of the Hadley circulation is within the range of 

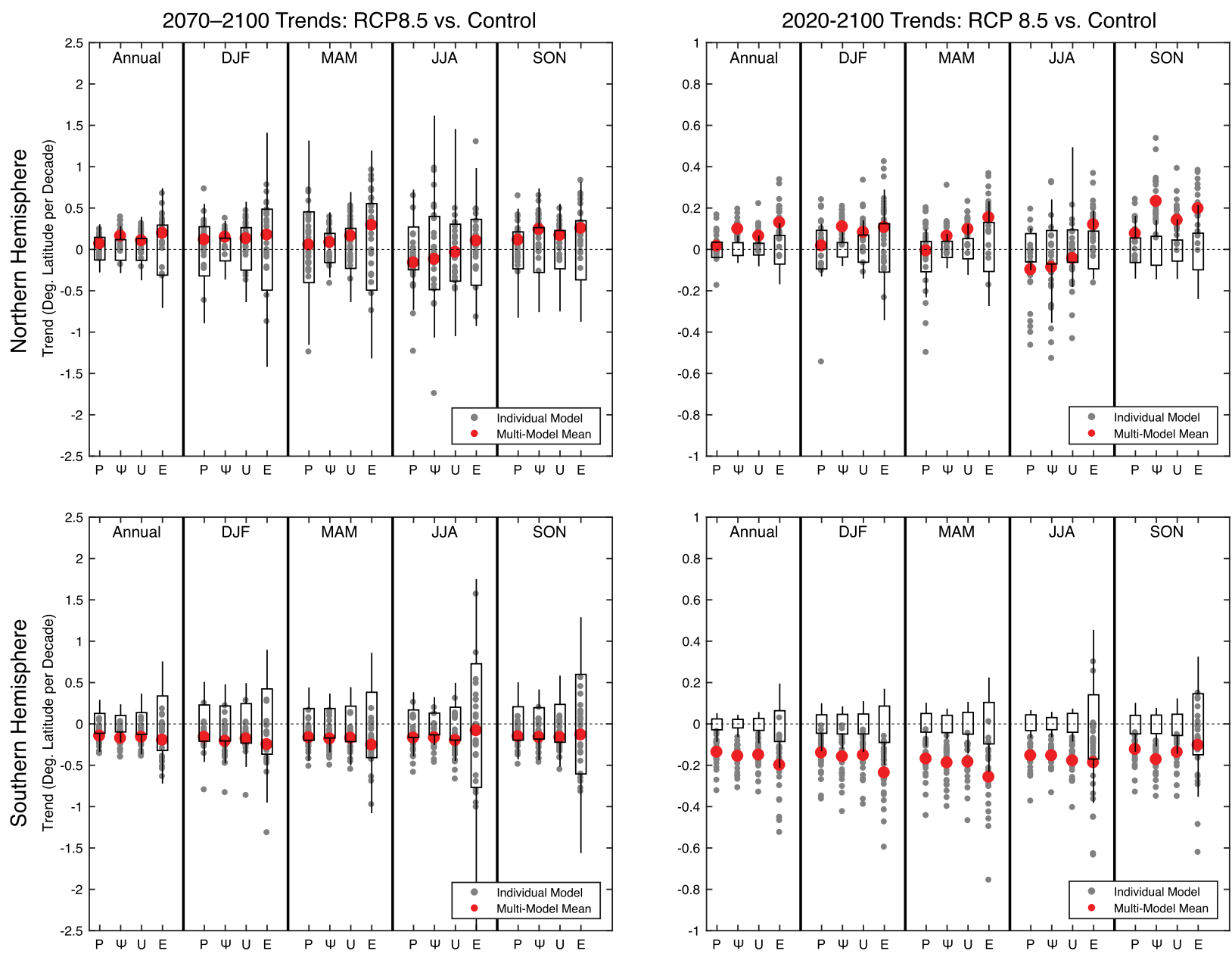

FIG. 9. As in Fig. 1, but comparing (left column) 2070-2100 trends from the RCP8.5 runs of CMIP5 models with 31-yr trends from the preindustrial control runs and (right column) 2020-2100 trends from the RCP8.5 runs of CMIP5 models with 81-yr trends from the preindustrial control runs. Gray dots indicate RCP8.5 trends from individual models, and the red dots indicate the multimodel mean RCP8.5 trends. Note that the scale on the ordinate is different in the right column.

global climate model projections for the 1980-2008 period (Fig. 1; Garfinkel et al. 2015; Allen and Kovilakam 2017; Davis and Birner 2017). In fact, in most cases, the observed trends do not even exceed the range of trends from the models' control runs, which arise exclusively from internal variability (Fig. 2). In the $\mathrm{SH}$, the observed tropical expansion during DJF and MAM falls in the upper 10th percentile of trends from the models' control runs (Fig. 2, bottom), but is better captured by the historical runs of the models forced with observed radiative forcings (Fig. 1, bottom). The large poleward expansion of the Hadley circulation in the SH during DJF and MAM is consistent with the influence of stratospheric ozone depletion and increasing greenhouse gases on the tropospheric circulation during these seasons (e.g., Polvani et al. 2011; Davis et al. 2016).

In the $\mathrm{NH}$, the observed tropical expansion during SON falls in the upper 10th percentile of the trends from both the control and historical runs of the models (Figs. 1 and 2, top). During this season, there are large poleward shifts in the circulation (subtropical high) over the North Atlantic Ocean (Fig. 4, bottom row; Fig. 6) that can only be captured by a small percentage $(<5 \%)$ of model ensemble members (Fig. 5). Outside of the Atlantic basin, the spatial structure of the recent $\mathrm{NH}$ circulation trends can be reproduced by model runs forced with observed SSTs (Fig. 3, right column), and are consistent with a shift in the PDO toward its negative phase during the early twenty-first century (Fig. 7; Allen et al. 2014; Allen and Kovilakam 2017; Amaya et al. 2018). However, the large poleward shift in the circulation over the North Atlantic during SON does not appear to be explained by the recent phase change of the PDO (Fig. 7).

The reason for the large circulation trends over the North Atlantic remains undetermined, and while these 
trends would be exceedingly rare, they are not outside the realm of natural variability suggested by the models (Fig. 5). Additionally, aerosol forcing, which may act to weaken the North Atlantic subtropical high in models (Fig. 8d), could bias the models' circulation trends in this region (see hypothesis 2 in section 5). These biases could be introduced by 1) an incorrect aerosol radiative forcing in models, 2) an improper sensitivity of the atmospheric circulation to aerosol forcing in models, or 3 ) some combination of those two factors.

Overall, the key conclusions from this study are that 1 ) the Hadley circulation has expanded poleward in both hemispheres since 1980,2) the recent tropical expansion has unique seasonal and regional characteristics, and 3) the majority of the recent circulation trends do not exceed the range of natural variability from global climate models. In general, 30-40-yr periods (the length of the observational record over the satellite era) are simply too short to detect anthropogenically forced circulation trends within a background of large natural variability (Fig. 9). Over the twenty-first century, much longer and consistent time series of circulation metrics will be necessary to definitively detect forced circulation trends in the observed climate record. In the meantime, we can only contrast the probabilities of the observed circulation trends occurring in climates with and without anthropogenic forcing.

Acknowledgments. We thank Clara Deser and three anonymous reviewers for helpful comments. We thank U.S. CLIVAR and ISSI (International Space Science Institute) for funding working groups on tropical expansion, members of these working groups for helpful discussions, and the U.S. CLIVAR and ISSI offices and sponsoring agencies (NASA, NOAA, NSF, DOE, ESA, Swiss Confederation, Swiss Academy of Sciences, University of Bern) for supporting these groups. We acknowledge WCRP's Working Group on Coupled Modelling, which is responsible for CMIP, and we thank the climate modeling groups for producing and making available their model output. For CMIP, the U.S. DOE PCMDI provides coordinating support and led development of software infrastructure in partnership with the Global Organization for Earth System Science Portals.

\section{APPENDIX}

\section{Calculation of Tropical Expansion Metrics}

To quantify poleward shifts in the zonal-mean tropospheric circulation, we calculate four metrics following Adam et al. (2018a,b).
For the $\Psi_{500}$ and $U_{\text {sfc }}$ metrics, we linearly interpolate each field to find its zero-crossing latitude in each hemisphere. For the $\Psi_{500}$ metric, the zero-crossing latitude is the latitude at which the $500-\mathrm{hPa}$ mean meridional streamfunction switches sign in the subtropics from thermally direct $(+$ in $\mathrm{NH},-$ in $\mathrm{SH})$ to thermally indirect ( - in $\mathrm{NH},+$ in $\mathrm{SH}$ ). For the $U_{\text {sfc }}$ metric, the zerocrossing latitude is the latitude at which the zonal-mean surface wind switches sign in the subtropics from negative (easterly) to positive (westerly). If an additional zero-crossing latitude that meets the same criteria is found within $20^{\circ}$ latitude poleward of the initial zerocrossing latitude, the metric is deemed poorly defined and is set to a missing value.

For the SLP and EDJ metrics, we find the latitude of the maximum value in the zonal-mean SLP and $850-\mathrm{hPa}$ zonal-mean zonal wind fields, respectively. The latitude of the maximum value is found using the following function:

$$
\phi_{\max }=\frac{\int_{\phi_{1}}^{\phi_{2}} F(\phi)^{n} \phi d \phi}{\int_{\phi_{1}}^{\phi_{2}} F(\phi)^{n} d \phi},
$$

where $F(\phi)$ is the zonal-mean field of interest (SLP or $850-\mathrm{hPa}$ zonal wind), $\phi$ is latitude, and $n$ is a smoothing parameter ( $n=\infty$ for zero smoothing). In the $\mathrm{SH}$, there are sharp peaks in the zonal-mean SLP and zonal-wind fields, and smoothing is not necessary to find the latitude of the maximum value in each field. In practice, we set $n=30$ to effectively turn off any smoothing for the SH metrics. In the NH, the peaks in the zonal-mean SLP and zonal wind fields are more poorly defined, and a smoothing parameter of $n=6$ provides the most accurate identification of the latitude of the maximum value in each field (Adam et al. 2018b).

For Figs. 4 and 5, we locate the SLP maximum at individual longitudes as follows. Following Choi et al. (2014), we smooth the SLP field at each longitude using a $30^{\circ}$ longitude running mean (or for Fig. 5, an average over $\left.60^{\circ} \mathrm{W}-0^{\circ}\right)$. Then, as for the zonal-mean SLP metric, we find the latitude of the maximum value using Eq. (A1) with a smoothing parameter of $n=6$.

\section{REFERENCES}

Adam, O., T. Schneider, and N. Harnik, 2014: Role of changes in mean temperatures versus temperature gradients in the recent widening of the Hadley circulation. J. Climate, 27, 7450-7461, https://doi.org/10.1175/JCLI-D-14-00140.1.

, K. M. Grise, P. Staten, I. Simpson, S. M. Davis, N. A. Davis, D. W. Waugh, and T. Birner, 2018a: TropD: Tropical width diagnostics software package Version 1.0. Zenodo, https:// doi.org/10.5281/zenodo.1157043. 
$-,-\longrightarrow,-,-$, and,$- 2018 \mathrm{~b}$ : The TropD software package: Standardized methods for calculating tropical width diagnostics. Geosci. Model Dev. Discuss., https://doi.org/10.5194/gmd-2018-124.

Allan, R., and T. Ansell, 2006: A new globally complete monthly historical gridded mean sea level pressure dataset (HadSLP2): 1850-2004. J. Climate, 19, 5816-5842, https://doi.org/10.1175/ JCLI3937.1.

Allen, R. J., and M. Kovilakam, 2017: The role of natural climate variability in recent tropical expansion. J. Climate, 30, 63296350, https://doi.org/10.1175/JCLI-D-16-0735.1.

—, S. C. Sherwood, J. R. Norris, and C. S. Zender, 2012: Recent Northern Hemisphere tropical expansion primarily driven by black carbon and tropospheric ozone. Nature, 485, 350-354, https://doi.org/10.1038/nature11097.

_, J. R. Norris, and M. Kovilakam, 2014: Influence of anthropogenic aerosols and the Pacific decadal oscillation on tropical belt width. Nat. Geosci., 7, 270-274, https://doi.org/10.1038/ngeo2091.

Amaya, D. J., N. Siler, S.-P. Xie, and A. J. Miller, 2018: The interplay of internal and forced modes of Hadley cell expansion: Lessons from the global warming hiatus. Climate Dyn., 51, 305-319, https://doi.org/10.1007/s00382-017-3921-5.

Barnes, E. A., and L. Polvani, 2013: Response of the midlatitude jets, and of their variability, to increased greenhouse gases in CMIP5 models. J. Climate, 26, 7117-7135, https://doi.org/ 10.1175/JCLI-D-12-00536.1.

Birner, T., S. Davis, and D. Seidel, 2014: The changing width of Earth's tropical belt. Phys. Today, 67, 38-44, https://doi.org/ 10.1063/PT.3.2620.

Booth, B. B. B., N. J. Dunstone, P. R. Halloran, T. Andrews, and N. Bellouin, 2012: Aerosols implicated as a prime driver of twentieth-century North Atlantic climate variability. Nature, 484, 228-232, https://doi.org/10.1038/nature10946.

Chen, S., K. Wei, W. Chen, and L. Song, 2014: Regional changes in the annual mean Hadley circulation in recent decades. J. Geophys. Res. Atmos., 119, 7815-7832, https://doi.org/ 10.1002/2014JD021540.

Choi, J., S.-W. Son, J. Lu, and S.-K. Min, 2014: Further observational evidence of Hadley cell widening in the Southern Hemisphere. Geophys. Res. Lett., 41, 2590-2597, https:// doi.org/10.1002/2014GL059426.

Compo, G. P., and Coauthors, 2011: The Twentieth Century Reanalysis Project. Quart. J. Roy. Meteor. Soc., 137, 1-28, https:// doi.org/10.1002/qj.776.

Davis, N., and T. Birner, 2017: On the discrepancies in tropical belt expansion between reanalyses and climate models and among tropical belt width metrics. J. Climate, 30, 1211-1231, https:// doi.org/10.1175/JCLI-D-16-0371.1.

— D. J. Seidel, T. Birner, S. M. Davis, and S. Tilmes, 2016: Changes in the width of the tropical belt due to simple radiative forcing changes in the GeoMIP simulations. Atmos. Chem. Phys., 16, $10083-10095$, https://doi.org/10.5194/acp-16-10083-2016.

Davis, S. M., and K. H. Rosenlof, 2012: A multidiagnostic intercomparison of tropical-width time series using reanalyses and satellite observations. J. Climate, 25, 1061-1078, https:// doi.org/10.1175/JCLI-D-11-00127.1.

Dee, D. P., and Coauthors, 2011: The ERA-Interim reanalysis: Configuration and performance of the data assimilation system. Quart. J. Roy. Meteor. Soc., 137, 553-597, https://doi.org/ 10.1002/qj.828.

ECMWF, 2009: ECMWF public datasets web interface: ERA Interim project. ECMWF, accessed 13 February 2017, http:// apps.ecmwf.int/datasets/data/interim-full-moda.
- 2014: ECMWF public datasets web interface: ERA-20C. ECMWF, accessed 13 February 2017, http://apps.ecmwf.int/ datasets/data/era20c-moda.

Fu, Q., C. M. Johanson, J. M. Wallace, and T. Reichler, 2006: Enhanced mid-latitude tropospheric warming in satellite measurements. Science, 312, 1179, https://doi.org/10.1126/science.1125566.

Garfinkel, C. I., D. W. Waugh, and L. M. Polvani, 2015: Recent Hadley cell expansion: The role of internal atmospheric variability in reconciling modeled and observed trends. Geophys. Res. Lett., $\mathbf{4 2}$, 10 824-10 831, https://doi.org/10.1002/2015GL066942.

Gelaro, R., and Coauthors, 2017: The Modern-Era Retrospective Analysis for Research and Applications, version 2 (MERRA-2). J. Climate, 30, 5419-5454, https://doi.org/ 10.1175/JCLI-D-16-0758.1.

GMAO, 2015: MERRA-2 tavgM_2d_slv_Nx: 2D, monthly mean, time-averaged, single-level, assimilation, single-level diagnostics, version 5.12.4. Goddard Earth Sciences Data and Information Services Center, accessed 13 February 2017, https://doi.org/10.5067/AP1B0BA5PD2K.

Grassi, B., G. Redaelli, P. O. Canziani, and G. Visconti, 2012: Effects of the PDO phase on the tropical belt width. J. Climate, 25, 3282-3290, https://doi.org/10.1175/JCLI-D-11-00244.1.

Grise, K. M., and L. M. Polvani, 2014: The response of midlatitude jets to increased $\mathrm{CO}_{2}$ : Distinguishing the roles of sea surface temperature and direct radiative forcing. Geophys. Res. Lett., 41, 6863-6871, https://doi.org/10.1002/2014GL061638.

$\longrightarrow$, and —, 2016: Is climate sensitivity related to dynamical sensitivity? J. Geophys. Res. Atmos., 121, 5159-5176, https:// doi.org/10.1002/2015JD024687.

Hartmann, D. L., and Coauthors, 2013: Observations: Atmosphere and surface. Climate Change 2013: The Physical Science Basis, T. F. Stocker et al., Eds., Cambridge University Press, 159-254.

$\mathrm{Hu}, \mathrm{Y}$., and Q. Fu, 2007: Observed poleward expansion of the Hadley circulation since 1979. Atmos. Chem. Phys., 7, 52295236, https://doi.org/10.5194/acp-7-5229-2007.

_ - L. Tao, and J. Liu, 2013: Poleward expansion of the Hadley circulation in CMIP5 simulations. Adv. Atmos. Sci., 30, 790795, https://doi.org/10.1007/s00376-012-2187-4.

JMA, 2013: JRA-55: Japanese 55-year reanalysis, monthly means and variances. NCAR Computational and Information Systems Laboratory Research Data Archive, accessed 13 February 2017, https://doi.org/10.5065/D60G3H5B.

Johanson, C. M., and Q. Fu, 2009: Hadley cell widening: Model simulations versus observations. J. Climate, 22, 2713-2725, https://doi.org/10.1175/2008JCLI2620.1.

Kanamitsu, M., W. Ebisuzaki, J. Woollen, S.-K. Yang, J. J. Hnilo, M. Fiorino, and G. L. Potter, 2002: NCEP-DOE AMIP-II reanalysis (R-2). Bull. Amer. Meteor. Soc., 83, 1631-1644, https://doi.org/10.1175/BAMS-83-11-1631.

Kang, S. M., and L. M. Polvani, 2011: The interannual relationship between the latitude of the eddy-driven jet and the edge of the Hadley cell. J. Climate, 24, 563-568, https://doi.org/10.1175/ 2010JCLI4077.1.

,-- J. C. Fyfe, and M. Sigmond, 2011: Impact of polar ozone depletion on subtropical precipitation. Science, 332, 951-954, https://doi.org/10.1126/science.1202131.

Karnauskas, K. B., and C. C. Ummenhofer, 2014: On the dynamics of the Hadley circulation and subtropical drying. Climate Dyn., 42, 2259-2269, https://doi.org/10.1007/ s00382-014-2129-1.

Kobayashi, S., and Coauthors, 2015: The JRA-55 reanalysis: General specifications and basic characteristics. J. Meteor. Soc. Japan, 93, 5-48, https://doi.org/10.2151/jmsj.2015-001. 
Kovilakam, M., and S. Mahajan, 2015: Black carbon aerosol-induced Northern Hemisphere tropical expansion. Geophys. Res. Lett., 42, 4964-4972, https://doi.org/10.1002/2015GL064559.

L'Heureux, M. L., S. Lee, and B. Lyon, 2013: Recent multidecadal strengthening of the Walker circulation across the tropical Pacific. Nat. Climate Change, 3, 571-576, https://doi.org/ 10.1038/nclimate1840.

Lucas, C., and H. Nguyen, 2015: Regional characteristics of tropical expansion and the role of climate variability. J. Geophys. Res. Atmos., 120, 6809-6824, https://doi.org/ 10.1002/2015JD023130.

_ - B. Timbal, and H. Nguyen, 2014: The expanding tropics: A critical assessment of the observational and modeling studies. Wiley Interdiscip. Rev.: Climate Change, 5, 89-112, https:// doi.org/10.1002/wcc. 251 .

Manney, G. L., and M. I. Hegglin, 2018: Seasonal and regional variations of long-term changes in upper-tropospheric jets from reanalyses. J. Climate, 31, 423-448, https://doi.org/ 10.1175/JCLI-D-17-0303.1; Corrigendum, 31， 1289-1293, https://doi.org/10.1175/JCLI-D-17-0881.1.

Mantsis, D. F., S. Sherwood, R. Allen, and L. Shi, 2017: Natural variations of tropical width and recent trends. Geophys. Res. Lett., 44, 3825-3832, https://doi.org/10.1002/2016GL072097.

Mantua, N. J., S. R. Hare, Y. Zhang, J. M. Wallace, and R. C. Francis, 1997: A Pacific interdecadal climate oscillation with impacts on salmon production. Bull. Amer. Meteor. Soc., 78, 1069-1080, https://doi.org/10.1175/1520-0477(1997)078<1069: APICOW $>2.0 . \mathrm{CO} ; 2$.

McLandress, C., T. G. Shepherd, J. F. Scinocca, D. A. Plummer, M. Sigmond, A. I. Jonsson, and M. C. Reader, 2011: Separating the dynamical effects of climate change and ozone depletion. Part II: Southern Hemisphere troposphere. J. Climate, 24, 1850-1868, https://doi.org/10.1175/2010JCLI3958.1.

Met Office Hadley Centre, 2000: Hadley Centre sea ice and sea surface temperature data set (HadISST), version 1.1. Met Office Hadley Centre, accessed 19 September 2017, https:// www.metoffice.gov.uk/hadobs/hadisst.

, 2013: Hadley Centre sea level pressure dataset, near real time product (HadSLP2r). NOAA/ESRL Physical Sciences Division, accessed 13 February 2017, https://www.esrl.noaa.gov/ $\mathrm{psd} / \mathrm{data} / \mathrm{gridded} / \mathrm{data}$.hadslp2.html.

Min, S.-K., and S.-W. Son, 2013: Multimodel attribution of the Southern Hemisphere Hadley cell widening: Major role of ozone depletion. J. Geophys. Res. Atmos., 118, 3007-3015, https://doi.org/10.1002/jgrd.50232.

NCEP, 2002: NCEP-DOE AMIP-II reanalysis. NOAA/ESRL Physical Sciences Division, accessed 17 April 2017, https://www. esrl.noaa.gov/psd/data/gridded/data.ncep.reanalysis2.html.

Newman, M., and Coauthors, 2016: The Pacific decadal oscillation, revisited. J. Climate, 29, 4399-4427, https://doi.org/10.1175/ JCLI-D-15-0508.1.

Nguyen, H., H. H. Hendon, E.-P. Lim, G. Boschat, E. Maloney, and B. Timbal, 2018: Variability of the extent of the Hadley circulation in the Southern Hemisphere: A regional perspective. Climate Dyn., 50, 129-142, https://doi.org/10.1007/ s00382-017-3592-2.

NOAA, 2014: Monthly NOAA-CIRES 20th century reanalysis (V2c). NOAA/ESRL Physical Sciences Division, accessed 13 February 2017, https://www.esrl.noaa.gov/psd/data/gridded/ data.20thC_ReanV2c.html.

Poli, P., and Coauthors, 2016: ERA-20C: An atmospheric reanalysis of the twentieth century. J. Climate, 29, 4083-4097, https://doi.org/10.1175/JCLI-D-15-0556.1.
Polvani, L. M., D. W. Waugh, G. J. P. Correa, and S.-W. Son, 2011: Stratospheric ozone depletion: The main driver of twentiethcentury atmospheric circulation changes in the Southern Hemisphere. J. Climate, 24, 795-812, https://doi.org/10.1175/ 2010JCLI3772.1.

Quan, X.-W., M. P. Hoerling, J. Perlwitz, H. F. Diaz, and T. Xu, 2014: How fast are the tropics expanding? J. Climate, 27, 19992013, https://doi.org/10.1175/JCLI-D-13-00287.1.

Rayner, N. A., D. E. Parker, E. B. Horton, C. K. Folland, L. V. Alexander, D. P. Rowell, E. C. Kent, and A. Kaplan, 2003: Global analyses of sea surface temperature, sea ice, and night marine air temperature since the late nineteenth century. J. Geophys. Res., 108, 4407, https://doi.org/10.1029/ 2002JD002670.

Saha, S., and Coauthors, 2010a: NCEP Climate Forecast System Reanalysis (CFSR) monthly products, January 1979 to December 2010. NCAR Computational and Information Systems Laboratory Research Data Archive, accessed 21 April 2017, https://doi.org/10.5065/D6DN438J.

, and Coauthors, 2010b: The NCEP Climate Forecast System Reanalysis. Bull. Amer. Meteor. Soc., 91, 1015-1058, https:// doi.org/10.1175/2010BAMS3001.1.

Santer, B. D., T. M. L. Wigley, J. S. Boyle, D. J. Gaffen, J. J. Hnilo, D. Nychka, D. E. Parker, and K. E. Taylor, 2000: Statistical significance of trends and trend differences in layer-average atmospheric temperature time series. J. Geophys. Res., 105, 7337-7356, https://doi.org/10.1029/1999JD901105.

Schmidt, D. F., and K. M. Grise, 2017: The response of local precipitation and sea level pressure to Hadley cell expansion. Geophys. Res. Lett., 44, 10 573-10 582, https://doi.org/10.1002/ 2017GL075380.

Seidel, D. J., Q. Fu, W. J. Randel, and T. J. Reichler, 2008: Widening of the tropical belt in a changing climate. Nat. Geosci., 1, 21-24, https://doi.org/10.1038/ngeo.2007.38.

Seviour, W. J. M., S. M. Davis, K. M. Grise, and D. W. Waugh, 2018: Large uncertainty in the relative rates of dynamical and hydrological tropical expansion. Geophys. Res. Lett., 45, 1106-1113, https://doi.org/10.1002/2017GL076335.

Simpson, I. R., T. A. Shaw, and R. Seager, 2014: A diagnosis of the seasonally and longitudinally varying midlatitude circulation response to global warming. J. Atmos. Sci., 71, 2489-2515, https://doi.org/10.1175/JAS-D-13-0325.1.

Solomon, A., and L. M. Polvani, 2016: Highly significant responses to anthropogenic forcings of the midlatitude jet in the Southern Hemisphere. J. Climate, 29, 3463-3470, https:// doi.org/10.1175/JCLI-D-16-0034.1.

, — - D. W. Waugh, and S. M. Davis, 2016: Contrasting upper and lower atmospheric metrics of tropical expansion in the Southern Hemisphere. Geophys. Res. Lett., 43, 10 496-10 503, https://doi.org/10.1002/2016GL070917.

Son, S.-W., and Coauthors, 2010: Impact of stratospheric ozone on Southern Hemisphere circulation change: A multimodel assessment. J. Geophys. Res., 115, D00M07, https://doi.org/ 10.1029/2010JD014271.

Staten, P. W., and T. Reichler, 2014: On the ratio between shifts in the eddy-driven jet and Hadley cell edge. Climate Dyn., 42, 1229-1242, https://doi.org/10.1007/s00382-013-1905-7.

Tao, L., Y. Hu, and J. Liu, 2016: Anthropogenic forcing on the Hadley circulation in CMIP5 simulations. Climate Dyn., 46, 3337-3350, https://doi.org/10.1007/s00382-015-2772-1.

Taylor, K. E., R. J. Stouffer, and G. A. Meehl, 2012: An overview of CMIP5 and the experiment design. Bull. Amer. Meteor. Soc., 93, 485-498, https://doi.org/10.1175/BAMS-D-11-00094.1. 
Thomas, J. L., D. W. Waugh, and A. Gnanadesikan, 2015: Southern Hemisphere extratropical circulation: Recent trends and natural variability. Geophys. Res. Lett., 42, 5508-5515, https:// doi.org/10.1002/2015GL064521.

Tokinaga, H., 2012: Wave and anemometer-based sea surface wind (WASWind), version 1.0.1. Kyoto University, accessed 13 February 2017, http://www.dpac.dpri.kyoto-u.ac.jp/ tokinaga/waswind.html.

_ , and S.-P. Xie, 2011: Wave- and anemometer-based sea surface wind (WASWind) for climate change analysis. J. Climate, 24, 267-285, https://doi.org/10.1175/2010JCLI3789.1.

Wang, C., S. Dong, A. T. Evan, G. R. Foltz, and S.-K. Lee, 2012: Multidecadal covariability of North Atlantic sea surface temperature, African dust, Sahel rainfall, and Atlantic hurricanes. J. Climate, 25, 5404-5415, https://doi.org/10.1175/ JCLI-D-11-00413.1.
Waugh, D. W., C. I. Garfinkel, and L. M. Polvani, 2015: Drivers of the recent tropical expansion in the Southern Hemisphere: Changing SSTs or ozone depletion? J. Climate, 28, 6581-6586, https://doi.org/10.1175/JCLI-D-15-0138.1.

_ , and Coauthors, 2018: Revisiting the relationship among metrics of tropical expansion. J. Climate, https://doi.org/ 10.1175/JCLI-D-18-0108, in press.

WCRP, 2011: Coupled Model Intercomparison Project, phase 5. Earth System Grid Federation, Lawrence Livermore National Laboratory, accessed 17 July 2017, https://esgf-node.llnl.gov/ search/cmip5.

Zhang, L., and C. Wang, 2013: Multidecadal North Atlantic sea surface temperature and Atlantic meridional overturning circulation variability in CMIP5 historical simulations. J. Geophys. Res. Oceans, 118, 5772-5791, https://doi.org/ 10.1002/jgrc.20390. 